\title{
US Presence and Grounds for Cooperation between the Islamic Republic of Iran and United States in Afghanistan
}

\begin{abstract}
${ }^{1}$ Center for Policy Research and International Student, University
Science Malaysia, 11800 Penang, Malaysia
mail: mehrzadarian@yahoo.com
\end{abstract}
Ali Akbar Ramazaniandarzi; Mehrzad Javadikouchaksaraei ${ }^{{ }^{*}}$
Received 13 January 2015; accepted 27 February 2015

Published online 1 April 2015

\begin{abstract}
To date, USA has not designed a policy to deal with Afghanistan and Iraq without Iran. One of the fundamental strategies of USA is to cooperate with the European Union, the Pacific, Russia, the Balkan Area, as well as the Caucasus the Middle East, North Africa, and Middle Asia. All of the countries relate to Iran in saving the Pacific. Iran is the most influential country in the area surrounding Afghanistan, the Middle East, and Northern Africa and Middle Asia. USA has to face Iran in the Middle East to meet the benefits of this relation. Therefore, such situation leads to the main question: does the attendance of USA in Afghanistan create the grounds for cooperation with Iran? Despite the existing disputes between the two governments, the attendance of USA in Afghanistan seems to have created new security, political, economic, and cultural fields for the cooperation of both countries.
\end{abstract}

Keywords: Iran, USA, Cooperation, Afghanistan

\section{Introduction}

After the fall of the imperial government of Iran in 1979, a new disarrayed government has emerged in a country that found itself in contrast with the interests of USA. The government showed a non-amicable behavior against USA and other similar countries in the biggest and crowded country in Western Asia that rules Hormuz and the Persian Gulf. In addition, the fall of Iran has definitely caused anxieties and disturbances in favor of USA and of martial agents starting from that period to the present. USA is judged with Iran, and the major strategy of USA comprising the goal of strategizing with Iran is ahead, and through such strategy, USA has surrounded and controlled the martial agents (Ansari, 2007). In spite of Iran and Washington not having any relation with each other since 1979, both regions have defined interests in Iran because of some regional changes. In addition, Iran and Washington have discovered that the goals and strategies of both regions are intermingled with those of Iran in the area. The September 11 event has redefined the modern international politics, and produced an excellent chance to forward the huge strategy of USA in relation to the political views of the East. This movement certainly aimed to produce the background for fixing the position of USA in the Middle East, especially in strategic power points, such as the Persian Gulf and the territories of the Caspian Sea.

Moreover, USA aimed to take steps toward multilateral challenges against crusaded values 
in Alghaedeh (an enemy of both Iran and USA), changing the political structure of Afghanistan by crushing the Taliban regime, and dismissing the Iraqi regime and the benefits of Iran (Bayman, 2010). In one viewpoint, USA attacks have somehow benefited Iran, as exemplified by the reduction of the influence of the two main rivals of Iran, namely, the Taliban and Saddam Hussein. In another viewpoint, controlling the cultivation and smuggling of narcotic substances are important objectives and create parallel directions between the two countries because the probability of establishing an Iran-Washington relation can be discussed in the regular regional frame, especially in Afghanistan and Iraq (Houghton, 2001). The situations in Afghanistan and Iraq can strengthen such relations, and this matter can strengthen the behavior of the two governments and can serve as a channel for the initiation of a discussion on the main matter. If this matter is planned with geopolitics, the outlook and leadership of both Tehran and Washington change in relation to Afghanistan and Iraq. This change becomes an excellent and suitable beginning toward solving the problems. Hence, the common interest point for the sake of Iran and USA is to solve the security crisis in Afghanistan and Iraq. This is a common need of both countries. Aside from the strategic surrounding of Iran by the US, another war is set by the latter against the nuclear program of Iran because some estimations show that Iran is the next target of US invasion (Souza, 2011).

Thus, the present research believes in the necessity of analyzing threats and the relationship in the context of the US invasion that have the same benefits for the region and the world. Moreover, the research believes in the importance of focusing threats and the same chance of cooperation between the two countries.

\section{Discussion}

Highly problematic relations between Iran and USA have been a major obstacle on the way to normalization for Afghanistan and the broader region. Ironically, although surrounded by destabilized and fragile states, Iran is perhaps the only regime in the region that forges internal stability, state functionality, and domestic legitimacy owing to the country's a tradition of successful mediation in regional conflicts in Iran's own neighborhood (from Tajikistan to Iraq), as well as the full respect for the sovereignty and borders of Afghanistan. For USA, the country has mainly focused in the country's relationship with Iran on deadlocks; issues unrelated to Afghanistan, such as Iran's nuclear program; and USA's policies toward the Middle East and Israel, as well as on the role of Iran in the regional competition for influence in Afghanistan (Murrage, 2009).

If the impending prospects for a certain shift in U. S. -Iranian relations begin to be realized, however, that change will at first not be in relation to these more contentious issues, but rather to those on which the parties share at least some common ground. Indeed, Iran's interests in steadying the situation in Afghanistan arise from major security challenges that are of concern not only to Iran and Afghanistan, but also to other major actors in the region as well as the United States, other Western actors and institutions, and the broader international community (Katzman, 2003).. The Persian Puzzle: The conflict between Iran and the USA" is the name of the book authored about the relation between Iran and the USA after the Islamic Revolution, written by "Kenneth M. Pollack" the outstanding and famous Analyzer of the Middle East published by Random House Publication. Polk, who had been one of the Analyzers of CIA, is presently trying to find complicate origins and roots of the barriers of the relation between Iran and the USA within the recent century in the process of his broad studies in "Borkinges Institute" (Rubin \& Batmanglich, 2008).

The particular characteristic of the book is that Polak has tried to find a way for understanding and explaining the present value of culture and policy of the modern Iran and, by doing so, to find reasons and grounds of the current conflicts in the relation between Iran and the USA with a historical point of view. Also Alireza Nader (2014) believe that Iran has substantial economic, political, cultural, and religious leverage in Afghanistan and interests in 
Afghanistan and its current policies in that country, therefor it should be considered it.

With their long-held sovereignty, these empires enjoy district integration and unique religion, great armies, superior and rich civilizations, and progressive management systems, which are concerned that the Iranians are more or less aware and proud of. In Pollack's opinion, this is the case for Iranians, as Pollack indicates the power in Iranian history. Second, Iran is the biggest Shiah country in the world (Bhadrakumar, 2010). During the recent five centuries, Iran is the only formal Shiah country in the world. Although $90 \%$ of Moslems in the world are Sunni, very limited countries exist in the world where the Shiah population is mainly composed of the peoples of Bahrain, Iraq, and Iran, or a large minority is composed of the peoples from Lebanon, Saudi, Syria, and Yemen. In these nations, only Iranians have a formal Shiite religion. Hence, Shiah provides attractive quality to the political culture of Iran. This religion has relevant dimensions and unique properties that are evident in the customs of the people. These properties deeply influence the behavior and political culture of Iranians. Thus, these properties add to the unique feel and historical national seclusion of Iranians; Iranians believe that Shiite is the key element of the citizens' national identity and that Arabs are synonymous to Shiah with Fars since the old century (Bruno, 2008).

The third factor is related to the colonization that Pollack has stated, which explains the history of the political identity of the 19th century. Iranians have stated that Europeans are barbarous, backward, and unbelievers. Suddenly Iranians have found themselves facing political, economic, and cultural attacks from Europeans who settled in the land of Iranians, which has created an invasion field with the help of other European powers. This matter has become an extremely humiliating and hopeless situation for Iranians, and has aggravated a deep distrust and xenophobia, followed by the reduction of complexities to create a balance of avenues for discussion on the main matter with selfgreatness (Berzegar, 2010). It has performed historical planning, examination, and dimension analysis of sociology to investigate the cultural and political changes of Lien, and the reason behind why Iranians have been viewed with skepticism. Given this situation, the discussion about the relation between Iran and USA has been opened, and it has mentioned this issue for the first time in USA, thus, students of Emma's filled the US embassy in Tehran. In addition, diplomats and American riflemen were taken as hostages. Pollack has discussed the bad behavior of USA, defended former kings, destroyed the government of $\mathrm{M}$. Mosaddegh, and called attention to the mistakes of USA in relation to Iran. Pollack has attempted to answer this key question in his book: how should policies be chosen to establish contact with Iran and solve difficulties? Pollack has described the military attack on Iraq in the "Treating Storm" book, and produced other formulas about Iran during this time. Choosing policies for military attacks to Iran or changing the Iranian government is completely wrong in Pollack's theory, and Pollack has written about the USA policy for Iraq (Afrasiabi \& Maleki, 2003).

During the 1990s, most Americans believed that Iraqis' hate emanated from Saddam's regime, and because of this displeasure, USA has thought that arming some of the displeasured people can destroy a government comfortably. This idea was proven wrong when USA was forced to spread and started attacks to destroy Saddam's regime. A similar thought about Iran currently exists. Perhaps Iranians have some displeasure with the Iranian government, but this assumption is not documented in terms of how ready Iranians are in destroying the system. From another perspective, Iran should be encouraged for each positive point, and vice versa, Iran should be punished in return for each negative point. One of the definitive goals is to convince Iran to accept the inspection of regular programs. The experience of Iraq shows that regular inspection is very influential and as such, Iran should also accept this inspection (Congressional Research Service, 2010).

However, a difference is apparent. Iraq's file must not be spoken about expanded economies for bidding or even using military power to modulate the desire of Iran to justify nuclear fuel 
production. Pollack has believed that based on the existing experiences of countries worldwide, Iran's profit should be researched more than that of USA. Thus, shaping society toward forbidding Iran is not impossible although difficult if Washington is successful in returning the Iran file to a security group (Gelb, 2006). Europe, Russia, Japan, and China are big partners in commerce and economy. Hence, Iranians do not have to worry about returning the country's file to a security group because this group cannot possible have the "courage" and "abilities to "boycott," and "punish" Iran. In this situation, maybe USA should only attempt to determine the situation for the country's allies. Therefore, Washington should receive a "written" guarantee for all powerful countries of the security council if Iran infringes the nuclear power production. The context is one where existing witnesses do not deny the attempt of this country to achieve mass care facilities, and any opposition should not be expressed with "boycott" or "punishment" of Iran. However, the concern is the advantage of this "written" guarantee, and even accepting this guarantee. France, Russia, and China obtain a favorable profit from being in contact with Iran presently. Hence, commercial changes between the two parties have increased in intensity (Gharekhan, 2011).

Moreover, these changes can result in delirium capital. In this situation, even a "written" guarantee cannot influence the guarantee for USA measures. In this condition, the result of the nuclear fuel production of Iran can be imagined comfortably after 10 decades when the continuous representative of USA in the security council in each section adheres to gathering the worldwide sanction against Iran. The only advice of Pollack to George W. Bush, former president of America, is to remember the famous speech of Ronald Reagan: A "good act" follows a "good act." The White House should prove his "good act" to Iran (Mercille ,2009). In contrast to the former conservatives of USA, some of Pollack's policy advice about Iran can be evaluated moderately. Pollack, who defended Iraq in his book about a military attack on this country, has argued at present against Iran in the "Persian Puzzle" book. Pollack supports a kind of sole contact with Iran's inflection, and uses the optimum from the weak points of Iran's foreign policy and the existing gap between the two political sides. Some articles have been published about Iran-USA relations. However, in most articles, a negative view about the speech is shown, which thinks that this relation is unilateral, and rejects any kind of relation. In this regard, books about this matter are lacking (Nader \& Laha, 2011). Most published books are focused on the relations between the two countries before the Iranian revolution and USA is known as an expansionist country. The writers of these books explained the image of USA in Iran. These books include "Foreign Relation of Iran from 20 to 57" written by Dr. Alireza Azghandi, "History of Iran and America Relation" written by Eskandar Daldam, and "Penetration of America to Iran" written by Ebrahim Sanjar. All of these books offer a negative insight on the relations between the two countries (Katzman, 2003).

Two articles among the articles studied revealed a positive attitude toward the relation between Iran and USA. One article is "Consequences of September 11th on National Interests of Iran" published by Nameh Magazine and written by Davoud Hermidas Bavand, which explained the international system after September 11. Dr. Bavand indicates new fields and ways for the relation at the end of the book. Dr. Bavand explained these fields in several parts: 1) struggle with Alghaedeh, 2) changing the structure of Iraq, and 3) changes in Iraq and conversion of the former active positive relation of the neighbor of Iran with USA to a passive relation. In the other article, Dr. Tahereh Ebrahimifar attempted to find a way along the same direction. However, these approaches are general (Hasan Waezi, 2011).

Articles published in Iran mostly have negative attitude toward the relation between Iran and USA. The article "Role of Bilateral Boycott of the USA against Iran" written by Daruish Akhavan Zanjani, discussed the relation between the two countries after the Islamic Revolution, as well as the useless and fruitless boycott of the USA. In addition, Iran is pictured as a very important and influential country in the region, 
and as such, any kind of relation with USA can be rejected (Luers, 2009).

Another article entitled "Another Kind of Colonization: Behavioral Model of the USA against Middle East Countries after 11th of September" written by Abass Bashiri, rejected the relations of two countries and regarded this relation as a colonial relation. First, Bashiri studied the relation between the two countries historically, but eventually the introduced USA as a colonialist country and rejected any relation with USA.

\section{Conclusion}

Among the aforementioned legal systems, the fairest system that complies with the fundamentals and basics of human rights is the legal system in which the husband's nationality is not imposed on the woman if a foreign woman marries a local man. In this system, the woman can acquire the nationality of her husband by making a request or going through brief paperwork. Moreover, in this system, if a local woman marries a foreign man, the woman is granted with the right to reject her primary nationality. This system not only stresses the independence of marriage from nationality and rejects any gender discrimination between women and men, but also preserves the woman's nationality after her marriage to a foreign man. In addition, in order to protect the unity of family, this system grants the woman the right to reject her primary nationality and acquire her husband's nationality.

\section{References}

A Project Iran workshop. (2006). Iranian objectives in Afghanistan: Any basis for collaboration with the US?. This project was organised by Centre for Strategic Studies, The CNA Corporation, November 29.

Afrasiabi, K., \& Maleki, A. (2003). Iran's foreign policy after 11 September. The Brown Journal of World Affairs, 9 (2): 255265.

Ansari, A. (2007). Confronting Iran, Published by Basic Books, 2.
Baer, R. (2008). Devil We Know: Dealing with the New Iranian Super Power, Grown, p. 23.

Bayman, D. (2001). Iran Security Policy in the Post Revolutionary. Era Washigton: Rand 2001.

Berzegar, K. (2010). Iran's foreign policy strategy after Saddam, The Washington Quarterly, 33(1): 178-182.

Bhadrakumar, M. K. (2010). A mad scramble over Afghanistan. Asia Times, 28 October 2008.

Bruno, G. (2008). Saudi Arabia and the future of Afghanistan. Council on Foreign Relations, of_afghanistan.html. Retrieved on 21 August 2009.

Congressional Research Service (2010). Obama has hung the Iranian democracy protesters out to dry in the 2010 budget. Available at: http://www.iranian.com/main/news/2009/0 9 /20/ Obama-has-hung-Iranian-democracyprotesters-outdry- 2010- budget.

D' Souza, S. M. (2011). Iran, US and Afghan conundrum. ISAS Insights, 132: 1-4.

Erlich, R. (2007). foreword by Robert Scheer, The Iran agenda: The Real Story of U.S Policy and Middle East Crisis, Published by Poli Point Press.

Gelb, B.A. (2006). Caspian oil and gas: Production and prospects. CRS Report for Congress, p. 3-4.

Gharekhan, C. R. (2011). "Is Arab Spring wishful thinking?. The Hindu, 22 June 2011.

Gonzalez, N. (2007). Engaging Iran: The Rise of Middle East Power House and Americans Strategic Choic. Green Wood Publishing group.

Goswami, N. (2009). The Obama administration 's Afghanistan-Pakistan policy: In need of an urgent rethink. Strategic Analysis, 33(4): 465-469.

Houghton, D. P. (2001). US Foreign Policy and the Iran Hostage Crisis, Cambridge University Press.

Katzman, K. (2003). Iran: current developments and US policy, CRS Issue Brief for Congress, June 26, 7.

Luers, W. (2009). Thomas R. Pickering, Jim Walsh, How to Deal with Iran?. New York. 
Mercille, J. (2009). The radical geopolitics of US foreign policy: the 2003 Iraq War. GeoJournal, 75(4): 327-337.

Murrage, D. (2009). Foreign Policy and Iran: American- Iranian Relation Since the Islamic Revolution. by Routledge.

Nader, A., \& Laha, J. (2011). Iran's balancing act in Afghanistan. Occasional Paper, RAND National Defence Research Institute, 12.

Raymond, H. (2003). The International Politics of Middle East. Manchester: University press.

Sudney, N. (1990). Fisher and William Ochsen. The Middle East: US: Mac Graw_Hill. ublications, 7 th edition 